\title{
Training Initiative for Psychiatry Post-graduate students (TIPPS) - a Unique Early Career Psychiatry Training Initiative in India and Its Response to the COVID-19 Pandemic
}

\author{
Satish Suhas ${ }^{1}$ - Amitkumar Chougule ${ }^{2}$. Raviteja Innamuri ${ }^{3}$. Swarna Buddha Nayok ${ }^{1}$. Sweta Sheth ${ }^{1}$. \\ Sachin Nagendrappa ${ }^{1} \cdot$ Krishna G. Patel $^{4} \cdot$ Sharanya B. Shetty ${ }^{5} \cdot$ Bhargavi Nagendra $^{6}$. Udayan Bhaumik ${ }^{7}$. \\ Sharnita Pugalenthi ${ }^{8} \cdot$ Gaurav Uppal $^{9} \cdot$ Girish N. Babu $^{10} \cdot$ Naren P. Rao $^{1} \cdot$ Rishikesh V. Behere $^{11}$
}

Received: 8 June 2021 / Accepted: 17 November 2021 / Published online: 14 January 2022

(c) Academic Psychiatry 2021

India is home to around 554 medical colleges with an annual intake of more than 83,075 students who undertake undergraduate training in medicine [1]. However, only about 243 of these medical colleges have structured postgraduate psychiatry teaching that caters to about 1003 psychiatry postgraduates per year [1]. There are various streams of postgraduate training-Doctor of Medicine (MD), Diploma in psychological medicine, Diplomate of National Boardthat are governed by different administrative bodies. The National Medical Commission (formerly known as the Medical Council of India) provides minimum required standards for postgraduate teaching centers, i.e., medical colleges, hospitals, and teaching institutes involved in postgraduate medical education. Postgraduate training in India lasts for 3 years, and the degree is awarded after a successful exit

Girish N. Babu

girisha1980@gmail.com

1 National Institute of Mental Health and Neurosciences, Bangalore, India

2 Cwm Taf Morgannwg University Health Board, Llantrisant, UK

3 Christian Medical College, Vellore, India

4 C. U. Shah Medical College and Hospital, Surendranagar, Gujarat, India

5 Kasturba Medical College, Mangalore, India

6 Bengaluru, India

Kolkata, India

Coimbatore, India

$9 \quad$ Sankalp Hospital, Amritsar, India

10 Department of Psychiatry, SDM Medical College, Dharwad, India

11 KEM Hospital Research Center, Pune, India examination compared to a 4-year residency training in the United States of America [2]. The postgraduate curriculum includes 18 months of training under inpatient and outpatient adult psychiatry; 3 months each of consultation-liaison psychiatry, addiction psychiatry, and child and adolescent psychiatry; 2 months each of neurology, community psychiatry, and elective posting; and 1 month each of forensic psychiatry, clinical psychology, and emergency or internal medicine. These medical colleges, hospitals, and teaching institutes involved in postgraduate medical education follow conventional teaching methods, including bedside teaching, didactic lectures, seminars, and journal clubs [3]. Both the National Medical council and the Diplomate of the National Board have made research dissertations a mandatory requirement to complete the postgraduate psychiatry course. However, evaluation and examination are governed by the university with which the teaching institute is affiliated. These universities may either be state-level medical universities, regional universities, or deemed universities (universities that are given autonomous status and powers by the Government of India to decide courses offered, syllabus, fees, training, and examination). Teaching and evaluation standards may vary depending on many factors such as the availability of teaching staff, caseload at the teaching hospital, size of the department, and affiliated university. This variability is more considerable in certain training areas such as psychotherapy, community and rehabilitation psychiatry, forensic psychiatry, child psychiatry, and research training. Hence, postgraduate trainees in India need to come on to a common platform and supplement their training by a peerled learning process. Such a platform would allow equitable access to common learning resources, trainees from low resource centers to benefit from the experiences of others from better-privileged training centers, and opportunities 
for residents to interact with mentors in a non-judgmental learning environment.

\section{Team Structure}

Training Initiative for Psychiatry Postgraduates (TIPPS) was started in 2015 by this initiative's administrators (R. V. B., G. B. N., N. P. R.). TIPPS learning initiatives are led by early to mid-career psychiatrists who have completed their training from India's different medical universities. The team consists of three administrators, one chief academic coordinator, and 20 early career psychiatry academic coordinators. The administrators are the senior-most members of this initiative. Their role is to provide leadership and planning of the academic initiatives of the group and mentor the team of academic coordinators. The chief academic coordinator is primarily responsible for the coordination and execution of the planned monthly activities. The academic coordinators conduct the academic discussions on the online group, and compile curated reading material and newsletters. The team meets every quarter to review the progress of the program and discuss new ideas and initiatives.

Of the 21 academic coordinators, seven are early-career faculty, six are private practitioners, five are senior residents, one is an international training fellow in the $\mathrm{UK}$, one is $\mathrm{PhD}$ scholar, and one is a Doctor of Medicine (DM) in Addiction Medicine. Eight of the 21 academic coordinators are women. Eighteen of the 21 academic coordinators were student members of the TIPPS platform and transitioned to an academic coordinator's role after obtaining their psychiatry degree. The organizational structure of TIPPS is depicted in Fig. 1.

Once a year, the academic committee invites members who have benefited from the initiative as postgraduate residents to volunteer to transition to academic coordinators' roles. This initiative's guiding principle is "learn and teach" and "teach and learn" to give back to the peer community. This provides opportunities for the academic coordinators' continued academic and professional enhancement after they have completed their training. The administrators and academic coordinators volunteer their time to conduct the academic programs on the online group. Participation in the online instant messenger group is free for postgraduate students. A registration fee is charged from delegates attending the annual in-person conference (details in the section below). This supports the maintenance costs of our website.

\section{Academic Activities of TIPPS}

The academic committee team conducts a range of academic activities. This includes the daily academic teaching and discussions on telegram. This instant messaging application-based E-learning platform has around 1515 (as of 10
August 2021) psychiatry trainees and early career psychiatrists from across India. It is a free and open platform that has grown through word-of-mouth with almost no attrition. By rotation, each academic coordinator gets to discuss a topic of the day in the group. The topics are pre-decided by the academic coordinators at the beginning of the month. Academic coordinators use problem-based learning strategies by way of case vignettes, multiple-choice questions, and customized videos. The discussant summarizes the discussions with references to reading material at the end of the week. TIPPS provides curated academic content in exam notes, prepared from standard references to simplify aid the postgraduates in their theory exam preparation. These include topics on basic sciences, psychology, sociology, and forensic psychiatry. These resources are available for free download [4-6]. A quarterly newsletter and resource material provides a round-up of interesting recent articles from leading journals, recent advances in psychiatry, upcoming conferences, and a creative section contributed by TIPPS members. TIPPS conducts webinars to orient postgraduates interested in pursuing further training abroad. Psychiatrists who have applied for membership into the Royal College of Psychiatrists (MRCPsych) and Fellowship of the Royal Australian and New Zealand College of Psychiatrists (FRANZCP) share their experiences. A document summarizing the Medical Training Initiative (MTI) process is available on the website [7].

Additionally, TIPPS organizes a yearly in-person conference called the Skills Training Exercise for Psychiatry Postgraduates (STEP) program. The conference is open only to psychiatry postgraduates. Workshop topics include essential clinical skills-Psychopathology and Mental Status Examination, evaluation of children, writing a formulation and management plan, interpreting psycho-diagnostics, neuroimaging, and electroencephalography. Postgraduates also present their research as oral or poster presentations. Conducted over 2 days in the cities of Bengaluru and Pune, about 1000 postgraduates have trained in these workshops over the last 4 years. A registration fee is charged for this conference which helps cover the maintenance costs of the online website. The academic activities of TIPPS are summarized in Table 1.

\section{Feedback from TIPPS Members}

An independent institutional ethics committee approved the collection of feedback from the members. The link to answer the optional feedback survey for participants was posted on the online instant messenger group for 3 weeks in October 2020. Three reminders were posted on the group once a week. We did not contact any members individually to take the survey. Potentially, all the group members had access to 
Fig. 1 Organizational Structure of TIPPS

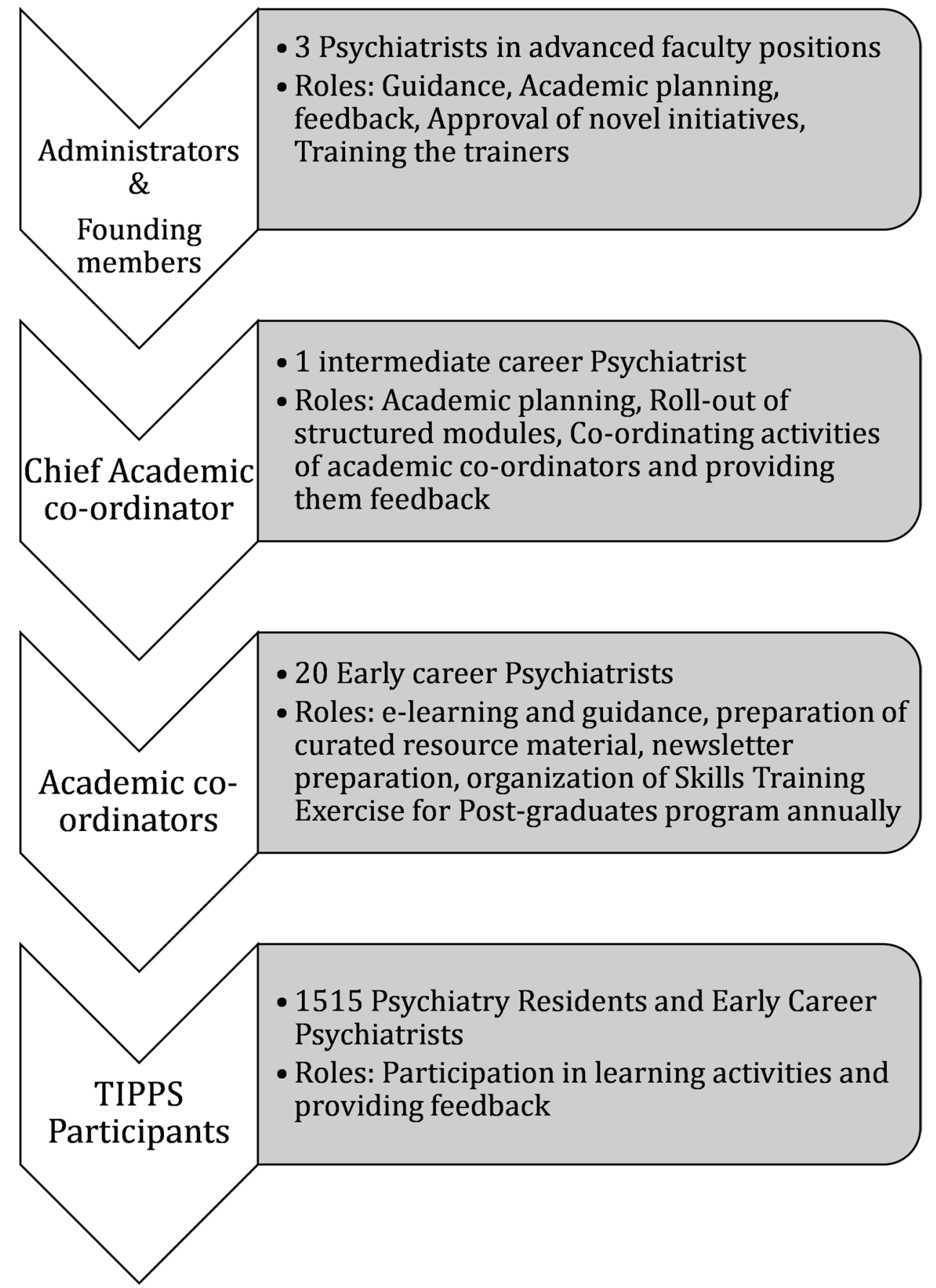

the survey $(N=1366)$ though we could not confirm whether all members accessed the group in this period. One hundred eleven ( $n$ approximately $8 \%$ ) participants responded to the survey.

Additionally, we have been taking periodic feedback from the STEP conferences. Among the survey participants, the majority (68\%) were in the 2nd or 3rd year of their training, and there was representation from almost all the states of India. Fifty-four percent were from private medical institutions, $34 \%$ from government colleges, and $12 \%$ from
Diplomate of National Board institutes. Seventy-six percent of respondents reported that their colleagues or seniors recommended the group to them. Fifty-eight percent had been members of the group for more than a year. The engagement rate (percentage of members who participated in the academic discussions after joining the online group) was $81 \%$, and $69 \%$ reported participating in the academic discussions at least once a week. Ninety-five percent of the respondents rated the quality of academic discussion and its relevance to their training as above average or outstanding. Ninety-two 
Table 1 Summary of the TIPPS learning initiatives

\begin{tabular}{|c|c|}
\hline E-Learning & $\begin{array}{l}\text { - Mode of delivery-synchronous through TIPPS Telegram group } \\
\text { - Educational activities through Telegram group } \\
\text { - Case-based discussion } \\
\text { - Multiple choice question-based discussion } \\
\text { - Clarifications of doubts posted by members } \\
\text { - Peer support and career guidance } \\
\text { - Teaching delivered by academic coordinator according to monthly academic teaching roster }\end{array}$ \\
\hline TIPPS Newsletter & $\begin{array}{l}\text { - Recent advances in Psychiatry } \\
\text { - Summary of Important Journal Articles } \\
\text { - Conference announcements } \\
\text { - Latest news in Psychiatry } \\
\text { - Extra-curricular contributions from TIPPS members } \\
\text { - Exam-oriented topics are covered in three volumes }\end{array}$ \\
\hline Published Documents by TIPPS & $\begin{array}{l}\text { - Psychiatry training opportunities in the UK } \\
\text { - Psychiatric Clinical Practice in times of Covid-19-A Practical Guide } \\
\text { - TIPPS OSCE Notes } \\
\text { - TIPPS Psychiatric history taking proforma } \\
\text { - TIPPS summaries of exam relevant clinical discussion }\end{array}$ \\
\hline STEP (in-person training program) & $\begin{array}{l}\text { - National conference dedicated to Psychiatry Postgraduates } \\
\text { - Exam relevant topics are discussed } \\
\text { - Focus on topics that are not covered in dept during Psychiatry post graduate training like } \\
\text { Forensic Psychiatry, Neuropsychiatry, Clinical Psychology, Neuro-radiology, Phenomenol- } \\
\text { ogy, communication skills, interviewing skills }\end{array}$ \\
\hline
\end{tabular}

percent had used the materials on the TIPPS website for their exam preparation. Eighty-eight percent agreed that the platform helped trainees to enhance their clinical skills and provided a forum to clarify their doubts. Though this survey obtained responses from a limited sample of the members, the results supported that TIPPS fulfilled its intended objectives. Obtaining feedback on the utility of academic activities is an ongoing continuous process for the academic committee, and we will plan a more structured survey in a larger sample of the group members in the future. A survey among the academic coordinators showed that most spent 1-4 h a week preparing for the academic discussions. Their primary motivation for volunteering as an academic coordinator was to give back to the community and transition from a student to a teacher. Academic coordinators reported being part of a peer group, appreciation from the students for their inputs, and an opportunity to learn by teaching as rewarding experiences.

\section{Impact on Residency Training and Response to the COVID Pandemic}

In March 2020, the country went into a nationwide lockdown in the wake of the COVID-19 pandemic. In many centers, residents were expected to fulfill obligations related to COVID-19 response in their institutes. Due to the COVID19 pandemic-related nationwide lockdown and resultant mobility restrictions, the number of people utilizing psychiatry outpatient and inpatient services declined. This had an impact on bedside and clinical training of psychiatry postgraduates. In-person classes were suspended-this significantly impacted conventional psychiatry residency training methods such as bedside teaching and lectures. There was uncertainty regarding the conduct of exit examinations. Many centers moved towards Objective Structured Clinical Examination (OSCE) formats as real patients would be unavailable for practical examinations. To continue providing clinical services, residents had to adapt to telemedicine formats quickly.

With these challenges, psychiatry teaching departments needed to adapt and make changes to their teaching formats. The TIPPS platform, an online one, was well placed to continue its academic activities even during the lockdown phase and attempted to fill the gaps in residency training. The group obtained feedback from its members to better understand their needs and modified its activities accordingly. These activities supplemented the efforts of their teaching departments. Some of the activities during this period included teaching modules on OSCEs and telemedicine. The National Board of Examination (NBE) opted to replace the traditional clinical examination process with unmanned OSCEs for the Diplomate of National Board examination. Gradually, several other training centers also opted for OSCEs as an exit exam. As the OSCEs are represented minimally in India's formal psychiatric training, postgraduates often lack the expertise required. The inclusion of OSCEs was unexpected for the postgraduates. The TIPPS group focused on OSCEs in August 2020 (a month before the Diplomate of National Board examinations). We conducted 
a webinar where speakers from various training setups from India, the UK, and Australia discussed the format and shared their experiences on OSCEs and tips for the preparation. Discussions on common case scenarios in OSCE, neuromodulation in psychiatry, interpreting brain imaging (computed tomography and magnetic resonance imaging), electroencephalogram, psychometric testing, forensic case scenarios, psychoeducation of patients and their relatives, and breaking bad news were conducted. The discussion was compiled into a document available on the website as a valuable resource for future reference [8]. We received positive informal feedback from those who attempted the DNB examination. The TIPPS team compiled the summaries of the clinical discussion delivered on the e-learning platform over the previous eight months and modified them into documents for last-minute revision before the university exams $[9,10]$. The Ministry of Health and Family Welfare, Government of India, released the Telemedicine guidelines in April 2020 [11]. TIPPS Team summarized the Telepsychiatry guidelines and provided essential information in a simplified form, easy to grasp for the postgraduates. This is available as a document "Psychiatric practice in the times of COVID-19: A practical guide" on the TIPSS website [12]. Traditionally, a new batch of postgraduates join the course in May-June of every year. In 2020, the new batches joined their training when their departments were not equipped to receive new trainees due to shunting human and healthcare resources to meet the needs of the pandemic. The resulting training needs related to fundamentals of psychiatry, clinical interview skills, and psychopathology were recognized. Subsequently, the TIPPS team in June-July 2020 conducted discussions on psychiatric history taking, mental status examination, concepts, and definitions of phenomenology to orient the new trainees.

\section{Future Directions}

With the multiple waves of COVID-19 looming, the challenges to psychiatric residency training will continue to persist into 2021. Some of the changes to psychiatric training and evaluation witnessed last year may now constitute the new normal. These include the increasing role of OSCE as a method of evaluation in the Indian examination system, telepsychiatry as a mode of delivery of mental health services [13], and virtual learning, where the focus is on userled teaching rather than teacher-led learning. As medical knowledge evolves, the new generation of doctors' learning needs is also rapidly changing. There is a pressing need for contemporary educators to adapt to e-learning modalities. Online learning initiatives are not new and are associated with varied satisfaction and acceptance rates $[14,15]$. It is accessible across barriers of time, and space making it a convenient learning medium.

Additionally, online learning initiatives provide a nonjudgmental atmosphere where the students can control the learning intensity and pace. However, this can lead to decreased in-person interactions; actively engaging a virtual audience, therefore, is challenging. Therefore, longterm studies need to be done to evaluate the effectiveness of implementing alternate means of education. Although more convenient, acceptable, and futuristic, e-Learning should be seen as an enhancement of conventional learning rather than a replacement. At TIPPS, we look forward to continuing this journey with newer e-learning methodologies to enhance psychiatry training and its learning experience.

\section{Declarations}

Ethical Considerations Ethical committee approval was obtained from the Institutional Ethics Committee of SDM University, Dharwad, India.

Disclosure On behalf of all authors, the corresponding author states that there is no conflict of interest.

\section{References}

1. India N. College and Course Search I NMC [Internet]. 2021. Available from: https://www.nmc.org.in/information-desk/colle ge-and-course-search. [Accessed on $1^{\text {st }}$ Aug 2021]

2. Washington University school of Medicine in St.Louis RR. Length of Residencies [Internet]. Residency Roadmap. 2021. Available from: https://residency.wustl.edu/residencies/length-of-resid encies/ [Accessed on $1^{\text {st }}$ Aug 2021]

3. Ranmuthugala G, Plumb JJ, Cunningham FC, Georgiou A, Westbrook JI, Braithwaite J. How and why are communities of practice established in the healthcare sector? A systematic review of the literature. BMC Health Serv Res. 2011;11:273.

4. Chougule AK. Psychiatry Exam Notes Volume 1 [Internet]. TIPPS. Available from: http://tipps.co.in/downloads/ [Accessed on $8^{\text {th }}$ Sept 2021]

5. Chougule AK. Psychiatry Exam Notes Volume 2 [Internet]. TIPPS. Available from: http://tipps.co.in/downloads/ [Accessed on $8^{\text {th }}$ Sept 2021]

6. Chougule AK. Psychiatry Exam Notes Volume 3 [Internet]. TIPPS. Available from: http://tipps.co.in/downloads/ [Accessed on $8^{\text {th }}$ Sept 2021]

7. Chougule AK. Psychiatry Training in the UK [Internet]. TIPPS. Available from: http://tipps.co.in/downloads/ [Accessed on $8^{\text {th }}$ Sept 2021]

8. Nayok S, Sheth S, Innamuri R. Objective Structured Clinical Examination (OSCE) [Internet]. TIPPS; Available from: http:// tipps.co.in/downloads/ [Accessed on $8^{\text {th }}$ Sept 2021]

9. Uppal G, Bhaumik U. Brain Stimulating TIPPS Volume 1 [Internet]. TIPPS. Available from: http://tipps.co.in/downloads/ [Accessed on $8^{\text {th }}$ Sept 2021]

10. Kiran R, Valipay K. Brain Stimulating TIPPS Volume 2 [Internet]. TIPPS. Available from: http://tipps.co.in/downloads/ [Accessed on $8^{\text {th }}$ Sept 2021] 
11. Telemedicine practice guidelines 2020. Board of Governors in supersession of the Medical Council of India. Ministry of Health and Family Welfare [Internet], Government of India. Available from: https://www.mohfw.gov.in>pdf>Telemedicine2020/. [Accessed on $8^{\text {th }}$ Sept 2021]

12. Rishikesh B, Naren PR, Girish BN, Sugnyani DP. Psychiatric practice in the times of COVID-19: a practical guide [Internet]. SUMANA; 2020 [cited 2021 May 27]. Available from: http:// tipps.co.in/downloads/ $\left[\right.$ [Accessed on $8^{\text {th }}$ Sept 2021]

13. Schuh Teixeira AL, Spadini AV, Pereira-Sanchez V, Ojeahere MI, Morimoto K, Chang A, et al. The urge to implement and expand telepsychiatry during the COVID-19 crisis: early career psychiatrists' perspective. Revista De Psiquiatria Y Salud Mental. 2020;13:174-5.
14. Coffey CS, MacDonald BV, Shahrvini B, Baxter SL, Lander L. Student perspectives on remote medical education in clinical core clerkships during the COVID-19 pandemic. Med Sci Educ. 2020;30:1577-84.

15. Singh K, Srivastav S, Bhardwaj A, Dixit A, Misra S. Medical education during the COVID-19 pandemic: a single institution experience. Indian Pediatr. 2020;57:678-9.

Publisher's Note Springer Nature remains neutral with regard to jurisdictional claims in published maps and institutional affiliations. 